Chronic Obstructive Pulmonary Diseases:

Journal of the COPD Foundation

COPD

\author{
A Statement of the COPD Foundation
}

\title{
The 2017 Update to the COPD Foundation COPD Pocket Consultant Guide
}

\author{
Barbara P. Yawn, MD, MSc ${ }^{1}$ Byron Thomashow, MD ${ }^{2}$ David M. Mannino, MD ${ }^{3}$ MeiLan K. Han, MD, MS ${ }^{4}$ \\ Ravi Kalhan, $\mathrm{MD}^{5}$ Stephen Rennard, $\mathrm{MD}^{6}$ Scott Cerreta ${ }^{7}$ James D. Crapo, MD ${ }^{8}$ Robert Wise, MD ${ }^{9}$
}

\begin{abstract}
The COPD Foundation Pocket Consultant Guide (PCG) was first released in 2007 as a practice tool for use at point of service for clinicians, especially primary care clinicians diagnosing and treating patients with chronic obstructive pulmonary disease (COPD). Over the years, the PCG has been supplemented with a mobile app that presents the tool in an online smart phone accessible version that also allows the clinician to enter patient specific data for guidance to next steps of diagnosis or management.

In November 2016, a new update of the PCG was released that incorporates a flow diagram for stepped care that includes the newest recommendation for diagnosis, assessment and treatment; including the broad use of dual bronchodilator therapy and consideration of asthma COPD overlap syndrome (ACOS). The current controversy regarding when to add inhaled corticosteroids (ICSs) is addressed to support clinical decision making.

The PCG comes in 2 versions, one with generic names for COPD drugs available in the United States and one with trade names for those drugs. The update continues to recommend spirometry for those at highest risk, also emphasizing the need to assess symptoms, exacerbation risks and comorbidity before selecting appropriate nonpharmacological as well as pharmacological therapy. The tool is designed to facilitate COPD management in daily practice.
\end{abstract}

\begin{abstract}
Abbreviations: COPD Foundation Pocket Consultant Guide, PCG; chronic obstructive pulmonary disease, COPD; asthma-COPD overlap syndrome, ACOS; inhaled corticosteroids, ICSs; Global initiative for chronic Obstructive Lung Disease, GOLD; spirometry grade 0, SG0; spirometry grade 1, SG 1; spirometry grade 2, SG2; spirometry grade 3, SG3; spirometry grade undefined, SGU; forced expiratory volume in 1 second, FEV $_{\mathbf{1}}$; computed tomography, CT; modified Medical Research Council, mMRC; COPD Assessment Test, CAT; phosphodiesterase 4 inhibitor, PDE-4; long-acting muscarinic antagonist, LAMA; long-acting beta2-agonist, LABA; forced vital capacity, FVC

Funding Support: Not applicable.

Date of Acceptance: March 23, 2017

Citation: Yawn BP, Thomashow B, Mannino DM, et al. A statement of the COPD Foundation: The 2017 update to the COPD Foundation COPD Pocket Consultant Guide. Chronic Obstr Pulm Dis. 2017;4(3):177-185. doi: https://doi.org/10.15326/jcopdf.4.3.2017.0136
\end{abstract}

1 Department of Family and Community Health, University of Minnesota School of Medicine, Minneapolis

2 Department of Medicine, Columbia University College of Physicians and Surgeons, New York, New York

3 Department of Preventive Medicine and Environmental Health, University of Kentucky, College of Public Health, Lexington

4 Division of Pulmonary and Critical Care Medicine, Department of Internal Medicine, University of Michigan Health System, Ann Arbor

5 Asthma and COPD Program, Northwestern University Feinberg School of Medicine, Chicago, Illinois
6 Clinical Discovery Unit, Early Clinical Development, AstraZeneca, Cambridge, United Kingdom and Department of Medicine, University of Nebraska Medical Center, Omaha

7 COPD Foundation, Washington, D.C.

8 Division of Pulmonary, Critical Care and Sleep Medicine, National Jewish Health, Denver, Colorado

9 Pulmonary and Critical Care, Department of Medicine, Johns Hopkins University School of Medicine, Baltimore, Maryland 


\section{Address correspondence to:}

Barbara P. Yawn, MD, MSc

$1963112^{\text {th }}$ Circle NE

Blaine, MN 55449

Phone: 5072613096

Email: byawn47@gmail.com

\section{Keywords:}

chronic obstructive pulmonary disease; COPD; guidelines; care recommendations; point of care; primary care; Global Initiative for Chronic Obstructive Lung Disease; GOLD

\section{Introduction}

Chronic obstructive pulmonary disease (COPD) continues to be a common condition among primary care patients and has risen to become the third leading cause of death in the United States. ${ }^{1}$ Yet it is still often diagnosed late and may be under or even untreated when it is recognized. ${ }^{2}$ For many practicing physicians and other clinicians, aggressive diagnosis and management of COPD was not a significant part of their training. Spirometry remains underused as a diagnostic and follow-up assessment and is often not easily accessible to primary care clinicians and patients. ${ }^{3-5}$

To supplement limited COPD-focused training and provide updated information, guidelines and care recommendations have been produced by both national and international organizations. These recommendations and guidelines are often not in a format to facilitate implementation or point-ofcare use. For example, the 132 page 2017 Global initiative for chronic Obstructive Lung Disease (GOLD) recommendations ${ }^{6}$ provide an important update and review of the evidence and recommendations for COPD management, but are lengthy.

The COPD Foundation produced its first brief, pointof-care COPD Foundation Pocket Consultant Guide (PCG) in 2007 with major updates in $2012^{7}$ and in November 2016. The new PCG is a 4" by 6" tri-fold card to be used at the point of care (office, emergency department or hospital) and is supplemented with online versions (www.copdpraxis.com) and a phone-friendly app for Apple products (search "COPD Foundation" in the App Store). An app for Android users will be released later in 2017. This tool is an expert opinion, consensus document that relies on published evidence but is not an evidence-based review of all elements of COPD diagnosis and management. It is designed to incorporate best practices and serve as a short summary to guide major clinical decisions during visits to the

office, emergency department or hospital. It is the work of the authors with input from many primary care health professionals who have reviewed and commented on its content.

\section{Highlights of the 2017 Update}

The new PCG begins with a practice flow diagram (Figure 1) to illustrate steps in diagnosing, assessing and grading COPD for management and ongoing care. Additionally, the PCG stresses that optimal COPD

\section{Figure 1. COPD Care Algorithm}

\section{THE COPD POCKET CONSULTANT}

\section{COPD Foundation Guide for Management of COPD}

COPD is defined by post bronchodilator FEV1/FVC ratio $<0.7$ on spirometry.

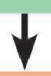

All COPD patients should have smoking cessation if smoking, vaccinations and be on a regular exercise program
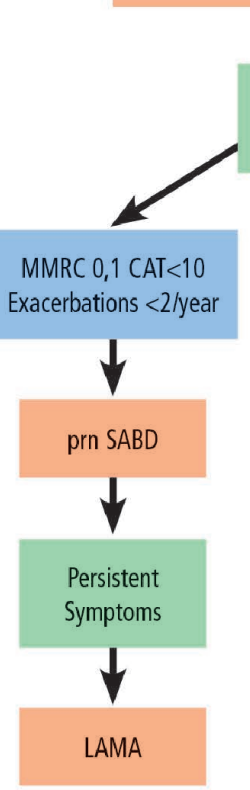

$\mathrm{FEV}_{1}=$ Forced expiratory volume 1 second; FVC=Forced vital capacity; CAT=COPD Assessment Test; MMRC=Dyspnea assessment test; $\mathrm{SABD}=$ Short acting bronchodilator - includes $5 \mathrm{SBA}=$ Short acting beta-2 agonist, SAMA=Short acting muscarinic agent, and combined SAMA/SABA; LAMA=Long acting muscarinic agent; LABA=Long acting beta- 2 agonist; $I C S=$ Inhaled corticosteroid 


\section{Figure 2. COPD Required Assessment for Therapy Guidance}

\author{
Assess Severity Domains \\ Each domain may have therapeutic implications. \\ Spirometry Grades: \\ SG 0 Normal spirometry does not rule out emphysema, chronic bronchitis, asthma, \\ or risk of developing either exacerbations or COPD. \\ SG 1 Mild: Post bronchodilator $\mathrm{FEV}_{1} / \mathrm{FVC}$ ratio $<0.7, \mathrm{FEV}_{1} \geq 60 \%$ predicted. \\ SG 2 Moderate: Post bronchodilator $\mathrm{FEV}_{1} / \mathrm{FVC}$ ratio $<0.7,30 \% \leq \mathrm{FEV}_{1}<60 \%$ predicted. \\ SG 3 Severe: Post bronchodilator FEV 1 FVC ratio $<0.7, \mathrm{FEV}_{1}<30 \%$ predicted. \\ SG U Undefined: $\mathrm{FEV}_{1} / \mathrm{FVC}$ ratio $>0.7, \mathrm{FEV}_{1}<80 \%$ predicted. This is consistent with \\ restriction, muscle weakness, and other pathologies.

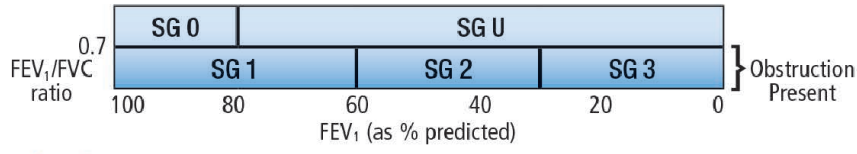 \\ Regular Symptoms: dyspnea at rest or exertion, cough, sputum. Use COPD \\ Assessment Test (CAT) or mMRC Breathlessness Scale to follow course of disease. \\ Exacerbations: two or more in the past year, especially if $\mathrm{FEV}_{1}<50 \%$ predicted \\ suggests high risk. \\ Oxygenation: severe hypoxemia: resting 02 sat $\leq 88 \%$ or arterial p $02<55 \mathrm{mmHg}$ \\ episodic hypoxemia: exercise or nocturnal desaturation. \\ Emphysema: reduced density on CT scan, can be localized, abnormal high lung \\ volumes, abnormal low diffusion capacity. \\ Chronic bronchitis: cough, sputum most days for at least 3 months in at least 2 years. \\ Comorbidities: defining and treating comorbid conditions, particularly cardiovascular, \\ anxiety and depression, are critical components of COPD care. \\ The presence of eosinophilia may help select those exacerbators who \\ could benefit from addition of ICS. \\ For those with recurrent exacerbations despite inhaled regimen consider: \\ a. Adding PDE4 Inhibitor Roflumilast (if chronic bronchitic) and/or \\ b. Adding Macrolide (if not active smoker) as immune modulator. \\ COPD patients with $\mathrm{FEV}_{1}<60 \%$ should have 02 saturation assessed. \\ a. Resting 02 sats $\leq 88 \%$ merit assessment for Oxygen therapy. \\ b. COPD patients with 02 sats $\leq 88 \%$ should have arterial blood gas tested and if significant \\ hypercapnea consider for sleep study and potential noninvasive ventilation. \\ COPD patients with FEV1 $\leq 45 \%$ should undergo Chest CT scanning and evaluation \\ for Lung Volume Reduction Surgery or if FDA approves, bronchoscopic Lung \\ Volume Reduction. \\ Annual low-dose CT scan for lung cancer screening - ages 55-79 years with 30 \\ packyears and cigarette smoking in the last 15 years.
}

care requires evaluation of all the severity domains: spirometry, symptoms, exacerbation frequency, oxygen requirements, presence of emphysema, chronic bronchitis and comorbidities (Figure 2). The flow diagram is color coded (blue for assessments, green for available tools or metrics and orange for therapies) to remind clinicians that several important tools and tests are available for comprehensive COPD assessment. Furthermore, repeated re-evaluation of patients is key and may be used to guide both pharmacotherapy and other COPD treatment decisions. The chart highlights the importance of smoking cessation, vaccinations, exercise, pulmonary rehabilitation, testing for Alpha-1 antitrypsin deficiency and again, evaluating comorbid conditions.

Spirometry is the basis for confirmation of a COPD diagnosis. The PCG continues to provide guidance for categorizing spirometry results, which fall into 3 major groups: normal, spirometry grade 0 (SG0); obstructive lung disease, spirometry grades 1-4 (SG1-4); and reduced lung function without obstruction, spirometry grade undefined (SG-U) (Figure 2). This panel also highlights the other roles of spirometry: to identify those with lower forced expiratory volume in 1 second $\left(\mathrm{FEV}_{1}\right)$ who may benefit from evaluation of hypoxemia at rest or with exercise (FEV 1 below $60 \%$ of predicted are candidates for pulse oximetry evaluation) and for those with $\mathrm{FEV}_{1}<45 \%$ predicted in whom you should consider computed tomography (CT) evaluation for emphysema that may be treatable with lung volume reduction surgery.

While not all patients fit into any 1-page algorithm, the simplified PCG fits most patients by grouping them into those with lower and higher symptom and functional status burdens using the modified Medical Research Council (mMRC) and the COPD Assessment Test $(\mathrm{CAT})^{8}$ scales which are short and feasible additions to routine primary care practice. The $\mathrm{mMRC}$ is a quick way to determine the activity and functional capacity of patients. The CAT incudes a broad range of questions across 8 domains including activity, sleep, fatigue, and symptoms such as daily cough. The care flow diagram adds the frequency of exacerbations to the symptom burden with the caveat that before diagnosis, COPD exacerbations are often referred to as recurrent and prolonged "bad" colds or episodes of "bronchitis.",

The flow chart (Figure 1) recognizes that COPD is progressive and that therapy is not static, requiring updates and enhancements as the patient's status changes. The medications can be thought of as a hierarchy centered around the current mainstay of COPD therapy, bronchodilators. Steps go up from "as needed short-acting bronchodilator" to "daily longacting bronchodilators." Dual bronchodilator therapy is acknowledged as a newly recommended, optional starting choice for all COPD patients requiring daily therapy and a likely appropriate starting choice for those who are more symptomatic (e.g., $\mathrm{mMRC}>2$ or CAT >10). The presence of 2 or more exacerbations a year is addressed by use of dual bronchodilator therapy plus consideration of the addition of daily inhaled 
corticosteroids (ICSs) if needed (e.g., "triple therapy"). The current controversy regarding when to start and continue ICS therapy for prevention of exacerbations is noted at the bottom of the list of domain assessments (Figure 2). Specifically, the presence of eosinophilia may help select those whose exacerbations are most amenable to ICS therapy.

Both of the first 2 panels of the PCG note that spirometry must be accompanied with assessment of symptom, exacerbations and functional status burden plus the other domains of severity (oxygenation, emphysema, chronic bronchitis and comorbidities) to determine the best diagnostic and therapeutic approaches. While symptoms and exacerbations drive most therapeutic decisions, the presence of significant emphysema or the presence of chronic bronchitis could raise possible roles for other specialized treatments such as lung volume reduction or a phosphodiesterase 4 (PDE-4) inhibitor, respectively.

The COPD drugs available in the United States are all listed as individual drugs and combinations with doses and available routes of administration-oral, inhaler and nebulized solutions. The list includes not only the mainstays of therapy, bronchodilators and corticosteroids, but also specialized therapy such as PDE-4 inhibitors for individuals with chronic bronchitis and refractory exacerbations and less commonly used add-on therapies such as methylxanthines and mucolytics. These treatment options are included in both the blue colored generic drug classification (Figure 3) and the orange trade name versions (Figure 4) of the PCG. The drugs listed include those approved for COPD treatment as well as some approved only for asthma such as ICS inhalers since they may be combined with dual long-acting muscarinic antagonists (LAMA) plus long-acting beta2-agonists (LABA) inhalers to facilitate triple therapy (ICS+LAMA+LABA). We have not included azthromycin in the flow chart since it is not in common use in primary care and its longterm use remains unclear. ${ }^{10}$ However, in the bullet points accompanying the flow chart, we have stressed that for those with recurrent exacerbations despite inhaled regimen, the following be considered: "Adding macrolide (if not active smoker) as immune modulator." (Figure 2)

Currently, diagnosis and management of COPD requires consideration of asthma and COPD overlap syndrome (ACOS) for individuals with a history of previous asthma, significant atopy or seasonal allergies such as allergic rhinitis. ${ }^{11}$ For these individuals who also have significant reversibility on post-bronchodilator spirometry testing, a diagnosis of ACOS may be appropriate requiring that baseline therapy includes both ICSs and long-acting bronchodilators. These are individuals for whom triple therapy may be the initial treatment of choice. The algorithm for ACOS consideration is found on the same panel as the detailed mMRC scoring. (Figure 5.)

The final panel of the PCG includes the detailed CAT questions to facilitate quick assessment for those practices unable to embed the CAT within their electronic medical records. The panel provides all of the questions and the scoring algorithm to facilitate its use at each visit to monitor a patient's progress. (Figure 6)

The PCG can also be linked to the mobile app for Apple iOS which is found by searching for "COPD Foundation" in the App store. This app allows health care professionals to individualize a patient's therapy by filling in a symptoms assessment, spirometry results and exacerbation history. The app highlights further testing and/or therapy, based on the specific patient's information.

Treatment of the COPD patient requires consideration of more than lung function and pulmonary symptoms. Much of the morbidity, mortality, and hospitalization risks experienced by those with COPD occurs due to the presence of comorbid conditions, particularly cardiovascular disease, depression, and anxiety. ${ }^{12}$ These may change the selection of therapy, as well as guide the need for adherence support and high priority of nonpharmacotherapies, such as pulmonary rehabilitation, that are effective for treating the depression and anxiety commonly accompanying COPD.

Individuals 50 years and older with a 20+ pack year history and less than 10 years of smoking abstinence are candidates for low dose CT scans to screen for lung cancer. ${ }^{13}$ (Figure 2) This U.S. Preventive Services Task Force recommendation is especially important to follow in individuals with COPD since COPD, ${ }^{14}$ and particularly the emphysematous form, is an independent risk factor for developing lung cancer. ${ }^{15}$

\section{Comparing the PCG 2017 to GOLD 2017}

The 2017 GOLD recommendations are an important desk reference and resource for in-depth review 


\section{Figure 3. Generic Version of COPD Drugs: Highlighted in Blue in the COPD Foundation Pocket Consultant Guide}

\begin{tabular}{|c|c|c|c|c|}
\hline Drug & \begin{tabular}{|l}
$\begin{array}{l}\text { Inhaler } \\
\text { (mcg) }\end{array}$ \\
\end{tabular} & \begin{tabular}{|l|} 
Solution for \\
Nebulizer (mg)
\end{tabular} & Oral & $\begin{array}{l}\text { Duration of } \\
\text { Action (hours) }\end{array}$ \\
\hline \multicolumn{5}{|c|}{ Beta 2 Agonists - Short Acting (SABA) } \\
\hline Albuterol & 90 (HFA-MDI) & $\begin{array}{l}0.63 / 3 \mathrm{ml} \\
1.25 / 3 \mathrm{ml} \\
2.5 / 3 \mathrm{ml}\end{array}$ & & $4-6$ \\
\hline Levalbuterol & 45 (HFA-MDI) & $\begin{array}{l}0.63 / 3 \mathrm{ml} \\
1.25 / 3 \mathrm{ml}\end{array}$ & & $6-8$ \\
\hline \multicolumn{5}{|c|}{ Beta 2 Agonists - Long Acting (LABA) } \\
\hline Salmeterol & 50 (DPI) & & & $12+$ \\
\hline Arformoterol & & $15 \mathrm{mcg} / 2 \mathrm{ml}$ & & $12+$ \\
\hline Formoterol Fumarate & & $20 \mathrm{mcg} / 2 \mathrm{ml}$ & & $12+$ \\
\hline Indacaterol Maleate & 75 (DPI) & & & 24 \\
\hline Olodaterol & $5(\mathrm{SMI})$ & & & 24 \\
\hline \multicolumn{5}{|c|}{ Anticholinergics - Short-Acting (SAMA) } \\
\hline Ipratropium Bromide & 17 (HFA-MDI) & $0.5 / 2 \mathrm{ml}$ & & $4-6$ \\
\hline \multicolumn{5}{|c|}{ Anticholinergics - Long-Acting (LAMA) } \\
\hline Tiotropium & 18 (DPI) & & & 24 \\
\hline Tiotropium & $5(\mathrm{SMI})$ & & & 24 \\
\hline Aclidinium Bromide & 400 (DPI) & & & 12 \\
\hline Glycopyrrolate Bromide & 15.6 (DPI) & & & 12 \\
\hline Umeclidinum & 62.5 (DPI) & & & 24 \\
\hline \multicolumn{5}{|c|}{ Long-Acting Anticholinergic plus Long-Acting B2-Agonist (LAMA/LABA) } \\
\hline Umeclidinium / Vilanterol & $62.5 / 25$ (DPI) & & & 24 \\
\hline Tiotropium / Olodaterol & $5 / 5$ (SMI) & & & 24 \\
\hline $\begin{array}{l}\text { Glycopyrrolate I } \\
\text { Formoterol Fumarate }\end{array}$ & 18/9.6 (MDI) & & & 12 \\
\hline Glycopyrrolate / Indacaterol & $15.6 / 27.5$ (DPI) & & & 12 \\
\hline \multicolumn{5}{|c|}{ Short Acting Anticholinergic plus B2-Agonist (SAMA/SABA) } \\
\hline Ipratropium Bromide / Albuterol & $20 / 100$ (SMI) & $0.5 / 2.5 / 3 \mathrm{ml}$ & & $4-6$ \\
\hline
\end{tabular}

\begin{tabular}{|c|c|c|c|c|}
\hline Drug & \begin{tabular}{|l} 
Inhaler \\
(mcg)
\end{tabular} & \begin{tabular}{|l|} 
Solution for \\
Nebulizer $(\mathrm{mg})$
\end{tabular} & Oral & \begin{tabular}{|l} 
Duration of \\
Action (hours)
\end{tabular} \\
\hline \multicolumn{5}{|l|}{ Methylxanthines } \\
\hline Theophylline (SR) & & & \begin{tabular}{|l|}
$100-600$ \\
mg (Pill)
\end{tabular} & $\begin{array}{l}\text { Variable } \\
\text { up to } 24\end{array}$ \\
\hline \multicolumn{5}{|l|}{ Mucolytic } \\
\hline $\mathrm{N}$-acetylcysteine (NAC) & & & $600 \mathrm{mg}$ & 12 \\
\hline \multicolumn{5}{|c|}{ Inhaled Glucocorticosteroids (ICS) } \\
\hline Beclomethasone* & \begin{tabular}{|l|}
40,80 \\
(HFA-MDI)
\end{tabular} & & & 12 \\
\hline Budesonide* & 90,180 (DPI) & \begin{tabular}{|l|}
$0.25 / 2 \mathrm{ml}$ \\
$0.5 / 2 \mathrm{ml}$
\end{tabular} & & 12 \\
\hline Fluticasone Propionate* & $\begin{array}{l}44-220 \text { (HFA) } \\
100,250 \text { (DPI) }\end{array}$ & & & 12 \\
\hline Fluticasone Furoate ${ }^{*}$ & 100,200 (DPI) & & & 24 \\
\hline Mometasone $^{*}$ & 220 (DPI) & & & 24 \\
\hline Ciclesonide $^{*}$ & 80,160 (HFA) & & & 12 \\
\hline
\end{tabular}

Inhaled Glucocorticosteroid plus Long Acting B2-Agonists (ICS/LABA)

\begin{tabular}{|l|l|l|l|l|}
\hline Budesonide / Formoterol & $\begin{array}{l}80 / 4.5^{*} \\
160 / 4.5\end{array}$ & & 12 \\
\hline Fluticasone / Salmeterol & $100 / 50^{*}$ & & & 12 \\
& $250 / 50$ & & & 12 \\
& $500 / 50^{*}$ (DPI) & & & 12 \\
\hline Fluticasone / Salmetero ${ }^{*}$ & $45 / 21$ & & & 12 \\
& $115 / 21$ & & 12 \\
& $230 / 21$ (HFA) & & & 12 \\
\hline Mometasone Furoate / & $100 / 5$ & & & 12 \\
Formoterol Fumarate Dihydrate & $200 / 5$ (HFA) & & & \\
\hline Fluticasone Furoate / Vilanterol & $100 / 25$ (DPI) & & & 24 \\
\hline Approved for Reducing COPD Exacerbations & & \\
\hline Fluticasone / Salmeterol & $250 / 50$ (DPI) & & & 12 \\
\hline Fluticasone Furoate /Vilanterol & $100 / 25$ (DPI) & & & 24 \\
\hline Tiotropium & 18 (DPI) & & & 24 \\
\hline Tiotropium & 5 (SMI) & & & 24 \\
\hline Roflumilast (PDE4 Inhibitor) & & & $500 \mathrm{mcg}$ & 24 \\
\hline
\end{tabular}

*FDA approved for Asthma

HFA=Hydrofluoroalkane $\quad M D I=$ Metered Dose Inhaler $\quad$ DPI=Dry Powder Inhaler $\quad$ SMI=Soft Mist Inhaler

of evidence, references and the resulting care recommendations. ${ }^{16}$ At 132 pages with a 45-page executive summary, these are references that few practicing clinicians will have time to review. The PCG summarizes much of the same care recommendations in one short pocket guide that is intended to be a quick reference used at the point of care.

There are other differences also. GOLD 2017 continues to use the 4 grades of COPD based on $\mathrm{FEV}_{1}$ values from post bronchodilator spirometry to categorize mild, moderate, severe and very severe COPD (Table 1). The PCG uses 5 grades to include normal (SGO) and a category of undefined which is reduced lung function without criteria for chronic obstruction (SGU). The other 3 categories are redefined to more closely fit with the American College of Physicians, American College of Chest Physicians, American Thoracic Society, European Respiratory Society Consensus Statement recommendations ${ }^{16}$ that identified high levels of evidence to support using an $\mathrm{FEV}_{1}<60 \%$ of predicted (labelled moderate COPD) as the cut off for increased risk of exacerbation and another important change at an $\mathrm{FEV}_{1}<30 \%$ of predicted where hypoxemia is more likely to require continuous oxygen therapy. (Table 1 )

The PCG authors believe the evidence from the COPD Genetic Epidemiology study and the SPIROMICS 


\section{Figure 4. Trade Name Version of COPD Drugs Highlighted in Orange in the COPD Foundation Pocket Consultant Guide}

\begin{tabular}{|c|c|c|c|c|}
\hline Drug & \begin{tabular}{|l} 
Inhaler \\
(mcg)
\end{tabular} & \begin{tabular}{|l|} 
Solution for \\
Nebulizer (mg)
\end{tabular} & Oral & \begin{tabular}{|l} 
Duration of \\
Action (hours)
\end{tabular} \\
\hline \multicolumn{5}{|c|}{ Beta 2 Agonists - Short Acting (SABA) } \\
\hline Albuterol & 90 (HFA-MDI) & $\begin{array}{l}0.63 / 3 \mathrm{ml} \\
1.25 / 3 \mathrm{ml} \\
2.5 / 3 \mathrm{ml}\end{array}$ & & $4-6$ \\
\hline Proair & 90 (HFA-MDI) & & & $4-6$ \\
\hline Proventil & 90 (HFA-MDI) & & & $4-6$ \\
\hline Ventolin & 90 (HFA-MDI) & & & $4-6$ \\
\hline Xopenex & 45 (HFA-MDI) & $\begin{array}{l}0.63 / 3 \mathrm{ml} \\
1.25 / 3 \mathrm{ml}\end{array}$ & & $6-8$ \\
\hline \multicolumn{5}{|c|}{ Beta 2 Agonists - Long Acting (LABA) } \\
\hline Serevent & 50 (DPI) & & & $12+$ \\
\hline Brovana & & $15 \mathrm{mcg} / 2 \mathrm{ml}$ & & $12+$ \\
\hline Perforomist & & $20 \mathrm{mcg} / 2 \mathrm{ml}$ & & $12+$ \\
\hline Arcapta Neohaler & 75 (DPI) & & & 24 \\
\hline Striverdi Respimat & 5 (SMI) & & & 24 \\
\hline \multicolumn{5}{|c|}{ Anticholinergics - Short-Acting (SAMA) } \\
\hline Atrovent & 17 (HFA-MDI) & & & $4-6$ \\
\hline Ipratropium Bromide & & $0.5 / 2 \mathrm{ml}$ & & $4-6$ \\
\hline \multicolumn{5}{|c|}{ Anticholinergics - Long-Acting (LAMA) } \\
\hline Spiriva Handihaler & 18 (DPI) & & & 24 \\
\hline Spiriva Respimat & 5 (SMI) & & & 24 \\
\hline Tudorza Pressair & 400 (DPI) & & & 12 \\
\hline Seebri Neohaler & 15.6 (DPI) & & & 12 \\
\hline Incruse Ellipta & 62.5 (DPI) & & & 24 \\
\hline \multicolumn{5}{|c|}{ Long-Acting Anticholinergic plus Long-Acting B2-Agonist (LAMA/LABA) } \\
\hline Anoro Ellipta & $62.5 / 25$ (DPI) & & & 24 \\
\hline Stiolto Respimat & $5 / 5(\mathrm{SMI})$ & & & 24 \\
\hline Bevespi Aerosphere & 18/9.6 (MDI) & & & 12 \\
\hline Utibron Neohaler & $15.6 / 27.5(\mathrm{DPI})$ & & & 12 \\
\hline \multicolumn{5}{|c|}{ Short Acting Anticholinergic plus B2-Agonist (SAMA/SABA) } \\
\hline $\begin{array}{l}\text { Ipratropium Bromide I } \\
\text { Albuterol }\end{array}$ & & $0.5 / 2.5 / 3 \mathrm{ml}$ & & $4-6$ \\
\hline DuoNeb & & $0.5 / 2.5 / 3 \mathrm{ml}$ & & $4-6$ \\
\hline Combivent Respimat & $20 / 100$ (SMI) & & & $4-6$ \\
\hline
\end{tabular}

\begin{tabular}{|c|c|c|c|c|}
\hline Drug & $\begin{array}{l}\text { Inhaler } \\
\text { (mcg) }\end{array}$ & \begin{tabular}{|l|} 
Solution for \\
Nebulizer (mg)
\end{tabular} & Oral & \begin{tabular}{|l} 
Duration of \\
Action (hours)
\end{tabular} \\
\hline \multicolumn{5}{|l|}{ Mucolytic } \\
\hline NAC & & & $600 \mathrm{mg}$ & 12 \\
\hline \multicolumn{5}{|c|}{ Methylxanthines } \\
\hline Theophylline (SR) & & & $100-600 \mathrm{mg}$ (Pill) & 24 \\
\hline Theo 24 & & & $100-400 \mathrm{mg}$ (Pill) & 24 \\
\hline Uniphyl & & & $400-600 \mathrm{mg}$ (Pill) & 24 \\
\hline \multicolumn{5}{|c|}{ Inhaled Glucocorticosteroids (ICS) } \\
\hline Qvar* & $\begin{array}{l}40,80 \\
\text { (HFA-MDI) } \\
\end{array}$ & & & 12 \\
\hline Pulmicort* $^{*}$ & 90, 180 (DPI) & $\begin{array}{l}0.25 / 2 \mathrm{ml} \\
0.5 / 2 \mathrm{ml} \\
\end{array}$ & & 12 \\
\hline Flovent* & $\begin{array}{l}44-220 \text { (HFA) } \\
100,250 \text { (DPI) }\end{array}$ & & & 12 \\
\hline Arnuity Ellipta* & 100,200 (DPI) & & & 24 \\
\hline Asmanex $^{*}$ & 220 (DPI) & & & 24 \\
\hline Alvesco* & 80,160 (HFA) & & & 12 \\
\hline
\end{tabular}

Inhaled Glucocorticosteroid plus Long Acting B2-Agonists (ICS/LABA)

\begin{tabular}{|l|l|l|l|l|}
\hline Symbicort & $\begin{array}{l}80 / 4.5^{*} \\
160 / 4.5 \text { (HFA) }\end{array}$ & & & 12 \\
\hline Advair Diskus & $100 / 50^{*}$ & & & 12 \\
& $250 / 50$ & & 12 \\
& $500 / 50^{*}$ (DPI) & & & 12 \\
\hline Advair* & $45 / 21$ & & & 12 \\
& $115 / 21$ & & 12 \\
& $230 / 21$ (HFA) & & & 12 \\
\hline Dulera* & $100 / 5$ & & & 12 \\
& $200 / 5$ (HFA) & & & \\
\hline Breo Ellipta & $100 / 25$ (DPI) & & & 24 \\
\hline Approved for Reducing COPD Exacerbations & \\
\hline Advair & $250 / 50$ (DPI) & & & 12 \\
\hline Breo Ellipta & $100 / 25$ (DPI) & & & 24 \\
\hline Spiriva Handihaler & 18 (DPI) & & & 24 \\
\hline Spiriva Respimat & 5 (SMI) & & & 24 \\
\hline Daliresp (PDE4 Inhibitor) & & & 500 mcg & 24 \\
\hline
\end{tabular}

*FDA approved for Asthma

HFA=Hydrofluoroalkane MDl=Metered Dose Inhaler $\quad$ DPl=Dry Powder Inhaler $\quad$ SMI=Soft Mist Inhaler COPD patients should be tested for alpha-1 antitrypsin deficiency, the genetic form of COPD. www.alpha-1foundation.org

trial $^{17,18}$ warrants the reintroduction of the SGO and SGU classifications within this pocket guide. Data from high resolution CT scans has shown that people with normal spirometry can have simple forms of chronic bronchitis and/or emphysema. ${ }^{17,18}$ Additionally, these individuals appear to experience considerable morbidity and may be at risk for disease progression. Symptomatic individuals with these spirometry grades should be evaluated for other signs of illness using other diagnostic tests and spirometry should be repeated periodically to assess possible progression. These individuals may be candidates for referral to a lung

specialist.

In the PCG, we have chosen to present a summary of COPD management in a simple flow sheet defining a hierarchy of therapies that mirror practice decisions. The flow sheet, supplemented by the assessment of all of the COPD severity domains presented, as well as assessment of ACOS, should allow for a clear and uniform approach to COPD management, monitoring and repeated assessments that are so important for the care of individuals with a chronic progressive condition. The PCG suggests dual bronchodilator therapy for symptomatic patients regardless of exacerbation risk, 


\section{Figure 5. Modified Medical Research Council Dyspnea Scale and Asthma-COPD Overlap Syndrome}

\begin{tabular}{|c|c|}
\hline \multicolumn{2}{|r|}{ mMRC Breathlessness Scale } \\
\hline Grade & Description of Breathlessness \\
\hline 0 & I only get breathless with strenuous exercise \\
\hline 1 & I get short of breath when hurrying on level ground or walking up a slight hill \\
\hline 2 & $\begin{array}{l}\text { On level ground, I walk slower than people of the same age because of } \\
\text { breathlessness, or have to stop for breath when walking at my own pace }\end{array}$ \\
\hline 3 & $\begin{array}{l}\text { I stop for breath after walking about } 100 \text { yards or after a few minutes on } \\
\text { level ground }\end{array}$ \\
\hline 4 & I am too breathless to leave the house or I am breathless when dressing \\
\hline \multicolumn{2}{|c|}{$\begin{array}{l}\text { Chris Stenton. The MRC breathlessness scale. Occup Med (Lond)(2008)58(3): 226-227 doi:10.1093/10ccmedikam162, Table } 1 . \\
\text { By permission of Oxford University Press on behalf of the Society of occupational Medicine. } \\
\text { A mMRC score of } 1 \text { or more suggests signnificant symptoms. }\end{array}$} \\
\hline
\end{tabular}

\section{Asthma COPD Overlap Syndrome (ACOS)}

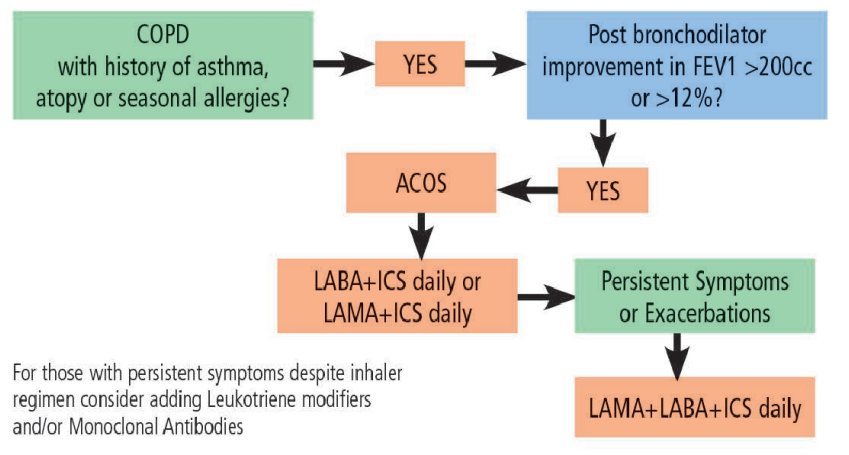

National Quit Smoking Line: 1-800-Quit NOW (784-8669)

COPD Foundation Information Line: 1-866-316-COPD (2673)

COPD 360: http://copd360social.org

Free Consultant Guide App- search "COPDFoundation" on App store

The COPD POCKET CONSULTANT is provided by the COPD Foundation as an educational resource only and should not be considered as offering medical advice. This information should not be used as a substitute for the exercise or receipt of a physician's independent professional judgement in providing advice, diagnosis or treatment for any medical or health condition. Updated March 2017

\section{COPDFOUNDATION}

www.copdfoundation.org

suggesting maximal bronchodilator therapy may be required prior to significant exacerbation risk. ${ }^{19}$

The COPD Foundation Pocket Consultant Guide was designed to be a readily accessible, practical guide for the assessment and management of the COPD patient at the point of care. It represents the opinion of the authors and is presented as a statement of the Board of Directors of the COPD Foundation but not that of any corporation or government body. As the understanding of COPD evolves and therapies advance, we expect the PCG to continue to evolve.

\section{Figure 6. The COPD Assessment Test}

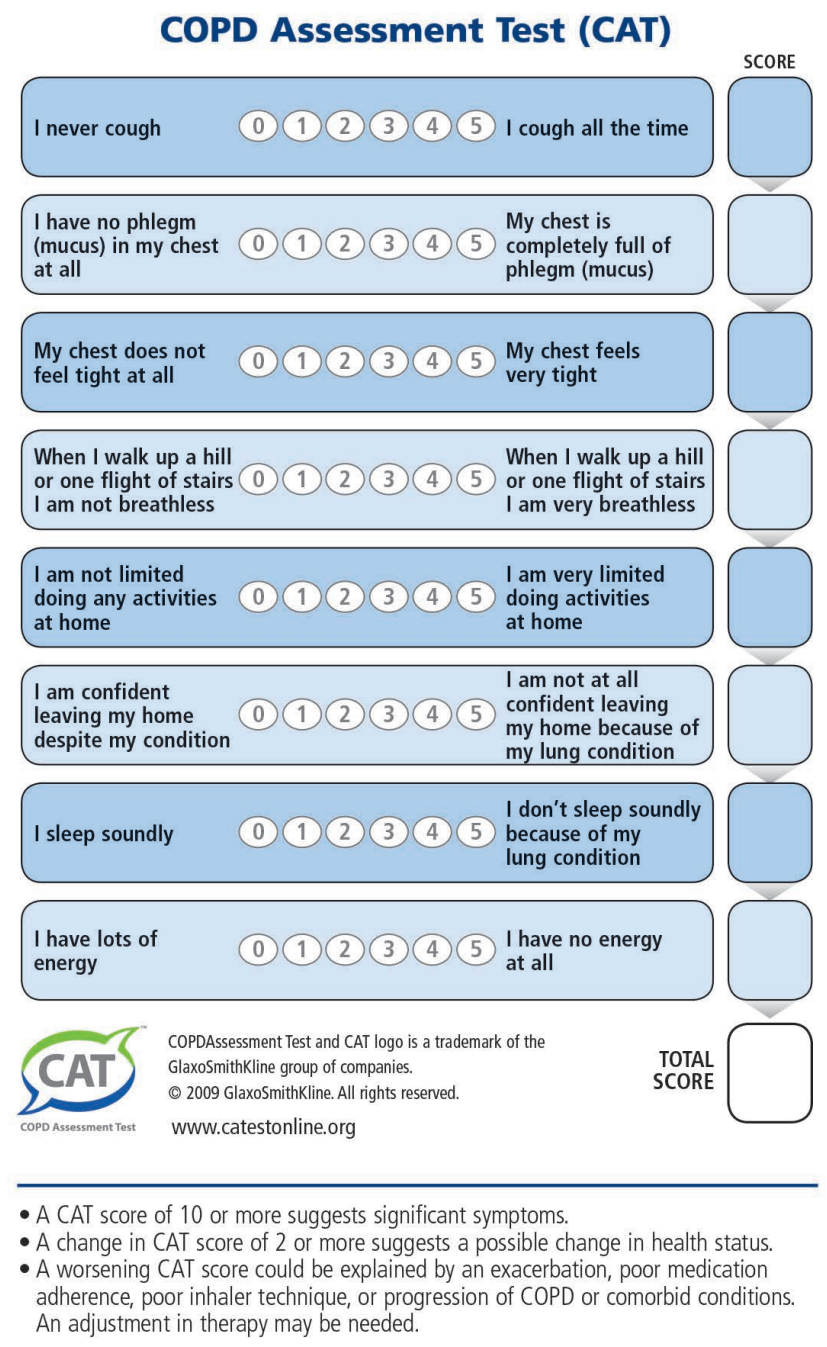

\section{Declaration of Interest}

Barbara P. Yawn reports receiving COPDrelated personal fees from Boehringer-Ingelheim, GlaxoSmithKline, AstraZeneca and Novartis and COPD-related research grant support from BoehringerIngelheim outside the submitted work. Scott Cerreta reports he has nothing to declare. MeiLan Han reports receiving personal fees from Sunovion, BoehringerIngelheim, GlaxoSmithKline, AstraZeneca and Novartis and receiving research grant support from Novartis and Sunovion outside the submitted work. David Mannino reports grants and personal fees from GlaxoSmithKline, personal fees from AstraZeneca, grants and personal fees from Novartis, personal fees from Amgen, grants and personal fees from Boehringer Ingelheim, personal 


\title{
Table 1. Comparison of Levels of COPD as Presented in Global Initiative for Chronic Obstructive Lung Disease 2017 and the 2017 COPD Pocket Consultant Guide
}

\author{
GOLD 2017 GOLD 1 - Mild $\mathrm{FEV}_{1}$ is $\geq 80 \%$ predicted \\ GOLD 2 - Moderate $\mathrm{FEV}_{1}$ is $50 \%-79 \%$ predicted \\ GOLD 3 - Severe $\mathrm{FEV}_{1}$ is $30 \%-49 \%$ predicted \\ GOLD 4 - Very Severe $\mathrm{FEV}_{1}$ is $<30 \%$ predicted
}

PCG 2017 SG 0 - Normal spirometry does not rule out emphysema, chronic bronchitis, asthma, or risk of developing either exacerbations or COPD.

SG 1 - Mild $\mathrm{FEV}_{1}$ is $>60 \%$ predicted

SG 2 - Moderate $\mathrm{FEV}_{1}$ is $30-60 \%$ predicted

SG 3 - Severe $\mathrm{FEV}_{1}$ is $<30 \%$ predicted

SG U Undefined: $\mathrm{FEV}_{1} / \mathrm{FVC}$ ratio $>0.7, \mathrm{FEV}_{1}<80 \%$ predicted. This is consistent with restriction, muscle weakness, and other pathologies.

fees from Merck, personal fees from Forest, personal fees from Up to Date, other from COPD Foundation, personal fees from Schlesinger Law Firm, non-financial support from Sunovion, outside the submitted work. Byron Thomashow reports receiving personal fees from Boehringer-Ingelheim, GlaxoSmithKline, AstraZeneca, and Novartis outside the submitted work. Robert Wise reports receiving personal fees from AstraZeneca, Boehringer-Ingelheim, Contrafect, GlaxoSmithKline, Merck, Novartis, Pulmonx, Roche-Genentech, Spiration, Sunovion, Teva and research grant support from AstraZeneca, Boehringer-Ingelheim, and GlaxoSmithKline outside the submitted work. Stephen
Rennard is employed by AstraZeneca, Cambridge, United Kingdom. He reports receiving personal fees from Baxter, AstraZeneca, Dailchi Sankyo, Forest, Penn Technology, Novartis, Pulmirix, and Takeda as well as research grant support from Pfizer, GlaxoSmithKline, Boehringer Ingelheim, Nycomed, Astra-Zeneca, Centocor, and Almirall outside the submitted work. Ravi Kahlan reports personal fees from Forest Laboratories, Boehringer Ingelheim, Merck, Smith Medical, AstraZeneca, CVS Caremark, and Aptus Health, as well as research grant support from Boehringer Ingelheim, GlaxoSmithKline, PneumRx (BTG), Spiration, all outside the submitted work. 


\section{References}

1. Kochanek KD, Murphy SL, Xu J, Tejada-Vera, B. Deaths: Final Data for 2014. Nat Vital Stat Rep. 2016; 65 (4): 1-121.

2. Ford ES, Croft JB, Mannino DM, Wheaton AG, Zhang X, Giles WH. COPD surveillance--United States, 1999-2011. Chest.2013;144(1):284-305.

doi: https://doi.org/10.1378/chest.13-0809

3. Yawn B, Mannino D, Littlejohn T, et al. Prevalence of COPD among symptomatic patients in a primary care setting. Curr Med Res Opin. 2009;25(11):2671-2677.

doi: https://doi.org/10.1185/03007990903241350

4. Price D, Crockett A, Arne M, et al. Spirometry in primary care case-identification, diagnosis and management of COPD. Prim Care Respir J. 2009;18(3):216-223.

doi: https://doi.org/10.4104/pcrj.2009.00055

5. Mapel DW, Dalal AA, Blanchette CM, Petersen H, Ferguson GT. Severity of COPD at initial spirometry-confirmed diagnosis: data from medical charts and administrative claims. Int J Chron Obstruct Pulmon Dis. 2011;6:573-581.

6. Global Initiative for Chronic Obstructive Lung Disease (GOLD). Global strategy for the diagnosis, management and prevention of COPD, GOLD 2017. GOLD website. http://goldcopd.org/ gold-2017-global-strategy-diagnosis-management-preventioncopd/ Published 2016. Accessed April 2017.

7. Rennard S, Thomashow B, Crapo J, et al. Introducing the COPD Foundation Guide for Diagnosis and Management of COPD, recommendations of the COPD Foundation. COPD. 2013;10(3):378-389.

doi: https://doi.org/10.3109/15412555.2013.801309

8. Zhang Q, Wang C, Ma Q, Modified Medical Research Council questionnaire and COPD assessment test are inconsistent. Eur Respir J. 2013;42: P2143.

9. Yawn BP, Wollan P, Rank M. Exacerbations in the pre- and postCOPD diagnosis periods. Pragmat Obs Res. 2013;4:1-6. doi: https://doi.org/10.2147/por.s41778

10. Siafakas N. Preventing exacerbations of COPD - Advice from Hippocrates. N Engl J Med. 2011;365: 753-754.

doi: https://doi.org/10.1056/NEJMe1106979

11. Postma DS, Rabe KF, The Asthma-COPD Overlap Syndrome. $N$ Engl J Med. 2015; 373:1241-1249.

doi: https://doi.org/10.1056/NEJMra1411863

12. Mapel D. Insights into COPD comorbidities from the OLIN study and other large databases. COPD. 2011; 8(6):397-379.

doi: https://doi.org/10.3109/15412555.2011.636555
13. Lowry KP, Gazelle GS, Gilmore ME, et al. Personalizing annual lung cancer screening for patients with chronic obstructive pulmonary disease: A decision analysis. Cancer. 2015;121(10):1556-1562. doi: https://doi.org/10.1002/cncr.29225

14. U.S. Preventive Services Task Force. Lung Cancer: Screening. Recommendation Summary. U.S. Preventive Services Task Force website. https://www.uspreventiveservicestaskforce.org/ Page/Name/tools-and-resources-for-better-preventive-care Published December 2013. Accessed April 2017.

15. de-Torres JP, Wilson DO, Sanchez-Salcedo P, et al. Lung cancer in patients with chronic obstructive pulmonary disease. Development and validation of the COPD Lung Cancer Screening Score. Am J Respir Crit Care Med. 2015;191(3):285291.

doi: https://doi.org/10.1164/rccm.201407-12100C

16. Qaseem A, Wilt TJ, Weinberger SE, et al, for the American College of Physicians, the American College of Chest Physicians, the American Thoracic Society, and the European Respiratory Society. Diagnosis and management of stable chronic obstructive pulmonary disease: A Clinical Practice Guideline update from the American College of Physicians, American College of Chest Physicians, American Thoracic Society, and European Respiratory Society. Ann Intern Med. 2011;155(3):179-191.

doi: https://doi.org/10.7326/0003-4819-155-3-201108020-0000

17. Regan EA, Lynch DA, Curran-Everett D, et al, for the COPD Genetic Epidemiology investigators. Clinical and radiologic disease in smokers with normal spirometry. JAMA Intern Med. 2015; 175(9):1539-1549.

doi: https://doi.org/10.1001/jamainternmed.2015.2735

18. Woodruff PG, Barr RG, Bleecker E, et al. Clinical significance of symptoms in smokers with preserved pulmonary function. $N$ Engl J Med .2016;3 74(19):1811-1821.

doi: https://doi.org/10.1056/NEJMoa 1505971

19. Oba Y, Sarva ST, Dias S. Efficacy and safety of long-acting beta ${ }^{2}$ agonist/long-acting muscarinic antagonist combinations in COPD: A network meta-analysis. Thorax. 2016;71(1):15-25. doi: https://doi.org/10.1136/thoraxjnl-2014-206732 